\title{
REFLEXÕES SOBRE 0 FINANCIAMENTO EDUCACIONAL: UMA REVISÃO CRÍTICA DOS AVANÇOS E RETROCESSOS DO INVESTIMENTO EM EDUCAÇÃO BÁSICA NO BRASIL
}

\author{
REFLECTIONS ON THE EDUCATIONAL FUNDING: A CRITICAL REVIEW OF THE \\ ADVANCES AND SETBACKS OF THE INVESTMENT IN BASIC EDUCATION IN
} BRAZIL

\section{REFLEXIONES SOBRE EL FINANCIAMIENTO EDUCACIONAL: UNA REVISIÓN CRÍTICA DE LOS AVANCES Y RETROCESOS DE LA INVERSIÓN EN LA EDUCACIÓN BÁSICA EN BRASIL}

Ivair Fernandes de Amorim*

\begin{abstract}
Resumo: Este texto apresenta uma revisão da literatura sobre financiamento educacional e da legislação vigente com intuito de realizar uma crítica às políticas públicas de financiamento da educação. Para tanto, retoma importantes documentos e leis que marcaram a Educação Nacional, em especial, os que foram determinantes para a consecução dos investimentos educacionais. Postula, ainda, sobre o quadro paradoxal, vivido atualmente, instaurado por políticas, de rígido contingenciamento, inauguradas pela Emenda Constitucional 95/2016 que ameaçam conquistas obtidas ao longo dos anos pelos esforços acadêmicos de pesquisadores dessa área, assim como pela pressão popular exercida por meio da sociedade civil organizada, por exemplo a Vinculação Constitucional de Recursos. Por fim, aponta a necessidade de sustentar o compromisso de democratização da Escola Pública Brasileira.
\end{abstract}

Palavras-chave: Financiamento da educação básica. Vinculação constitucional de recursos. Emenda constitucional 95/2016.

\begin{abstract}
This text presents a review of the literature on educational funding and the current legislation, in order to provide a critical analysis the Brazilian public policies. To do so, it resumes important documents and laws that have marked the National Education, in particular, those ones that were determinant for the achievement of educational investments. It also postulates the paradoxical situation experienced at the present moment established by rigid contingency policies, launched by the Constitutional Amendment 95/2016, that threaten important accomplishments over the years by the academic efforts from researchers in this area, as well as by popular pressure exerted by means of the Organized civil society, for example the Constitutional binding of resources Finally, it points out the need to sustain the Brazilian Public School democratization commitment.
\end{abstract}

Keywords: Basic education funding. Constitutional binding of resources. Constitutional amendment 95/2016.

\footnotetext{
* Doutor em Educação Escolar pela UNESP. Professor da Educação Básica, Técnica e Tecnológica - Área: Educação/Pedagogia do Instituto Federal de Educação, Ciência e Tecnologia de São Paulo, campus Votuporanga. E-mail: ivairpedagogo@ifsp.edu.br
} 
Resumen: En este trabajo se presenta una revisión de la literatura sobre el financiamiento de la educación, y la legislación vigente, con el fin de realizar una crítica a las políticas públicas de financiamiento educacional. Para ello, retoma importantes documentos y leyes que han marcado la educación nacional, en particular, algunos fundamentales para el logro de las inversiones en educación. Postula, todavía, en el panorama paradójico que se vive en el momento, a causa de políticas de frente duras de contingencia, inauguradas por la Enmienda Constitucional 95/2016, que amenazan importantes logros obtenidos en los últimos años gracias a los esfuerzos académicos de los investigadores en este campo, así como la presión pública ejercida a través de la sociedad civil organizada, por ejemplo el Enlace Constitucional de Recursos. Por último, señala la necesidad de mantener el compromiso con la democratización de la Escuela Pública Brasileña.

Palabras-clave: Financiamiento de educación básica. Enlace Constitucional de Recursos. Enmienda constitucional 95/2016.

Tudo isso exige despesas consideráveis. (Lourenço Filho, 1976, p. 186)

As despesas às quais se referia Lourenço Filho, em meados da década de 1970, são aquelas oriundas da manutenção das atividades educacionais. Este importante pensador brasileiro acentua que, desde a instalação de prédios e de seus mobiliários até a contratação de quadros profissionais, a educação exige o empenho de grandes somas em dinheiro. Essa é uma constatação, ao mesmo tempo, de uma certa obviedade e de grande relevância que leva a uma recorrente pergunta, nos debates educacionais de nosso país: Quanto a sociedade brasileira está disposta a pagar pela educação?

Antes de iniciarmos as reflexões a que nos propomos neste texto, é necessário salientar que, dentre outros, existem três determinantes das políticas de financiamento educacional que não podem escapar a uma análise crítica, a saber, $\left(1^{\circ}\right)$ a concepção que se tem de Estado e o papel que este assume mediante o financiamento da educação pública; $\left(2^{\circ}\right)$ o contexto histórico no qual as políticas de financiamento são forjadas e implementadas e $\left(3^{\circ}\right)$ a legislação educacional vigente.

Não esgotaremos a discussão destes determinantes neste texto, no entanto, algumas considerações são necessárias.
Em relação à concepção de Estado, os pesquisadores (CARNOY, 1987; CURY, 2007; RODRIGUES, C. A. F., 2001; RODRIGUES, A. T, 2000; OLIVEIRA, 2002b) apontam para três principais concepções que, ao longo do tempo, influenciaram os modos organizativos das estruturas estatais, quais sejam, a concepção liberal, a concepção marxista e a concepção de Estado de Bem Estar Social.

No cenário brasileiro, tem prevalecido a concepção de estado liberal. Rodrigues (2001) enfatiza que esta concepção é de cunho individualista e preconiza a relação livre entre sujeitos, regulada pelas regras de mercado. Esta tendência esteve sempre presente ao longo da história de nosso país e foi fortemente retomada na década de 1990 com o chamado Neoliberalismo.

Em terras brasileiras, o discurso Liberal/Neoliberal serviu de pretexto ora para uma omissão estatal mediante às responsabilidades financeiras concernentes à atividade educativa, ora para a destinação de verbas públicas a instituições educacionais privadas.

Já em relação ao histórico do financiamento educacional em território nacional, uma breve visita à literatura especializada (ANDREOTTI; LOMBARDI; MINTO, 2010; BRASIL, 2010; CURY, 2007; OLIVEIRA, 2002a, 2002b) demonstra que o investimento 
em educação no Brasil foi negligenciado desde a chegada dos colonizadores portugueses até o advento da Lei de Diretrizes e Bases da Educação Nacional no 9394/96 e a consolidação da Política de Fundos (FUNDEF e FUNDEB). Tal situação remete ao fato de que a insuficiência de recursos para a realização de uma educação de qualidade tem sido uma constante na História da Educação Brasileira.

Por fim, no que concerne à legislação educacional vigente, temos uma situação que só pode ser entendida enquanto um paradoxo. A compreensão da legislação educacional remete-nos às leis de maior prevalência que, no caso da Educação, seriam a Constituição Federal (CF) e a Lei de Diretrizes e Bases da Educação Nacional (LDBEN).

Uma análise das diferentes Constituições promulgadas na história de nosso país, assim como, das LDBENs aponta que a agenda proposta para o financiamento da educação gira em torno de questões que foram, efetivamente, propostas na década de 1930 e, que permanecem sem uma resolução decisiva até a atualidade.

No entanto, o atual paradoxo não reside no fato do sistemático descumprimento dos preceitos legais, característica recorrente dos governos que se sucederam nas três esferas administrativas de nossa Nação. O paradoxo encontra-se no fato de que as atuais manobras governamentais culminaram na inserção de mecanismos legais que neutralizam garantias importantes para manutenção de políticas de financiamento educacional.

Dessa forma, neste texto, nos deteremos neste último aspecto por considerá-lo de suma importância para uma revisão crítica do financiamento educacional Brasileiro.

\section{Do Manifesto dos Pioneiros da Educação à Emenda Constitucional $n^{0} 95$ de 15/12/2016}

A atualidade é propícia ao debate educacional devido à uma sucessão de fatos, político-partidários e também de mobilização da sociedade civil, que culminaram na sanção de importantes marcos legais.

Um dos pontos de grande relevância advém de importante exemplo de mobilização e articulação da sociedade civil junto aos órgãos governamentais que culminou na aprovação tardia ${ }^{1}$ do Plano Nacional de Educação (PNE), por meio da Lei $n^{\circ} 13.005$ de 25 junho de 2014. Este fato destacou-se, ao menos a princípio, como uma possibilidade de novas conquistas educacionais viabilizadas por uma política pública social voltada ao desenvolvimento integral de todos os cidadãos.

No entanto, como já afirmamos, a agenda educacional, em especial no âmbito do financiamento educacional, tem apresentado pautas recorrentes. Neste sentido, convém rememorar dois importantes marcos da luta pela democracia brasileira.

O primeiro, é o Manifesto dos Pioneiros da Educação Nova de $1932^{2}$ que completa, neste ano, oitenta e cinco anos de sua publicação.

O Manifesto dos Pioneiros da Educação Nova pode, pois, ser considerado um importante legado que nos é deixado pelo século XX. É um marco de referência que inspirou as gerações seguintes, tendo influenciado, a partir de seu lançamento, a

\footnotetext{
${ }^{1} \mathrm{~A}$ atual lei do PNE é fruto das proposições feitas pela Conferência Nacional de Educação de 2010 (CONAE 2010) para o decênio 2011-2020, no entanto, a tramitação do referido projeto de lei fez com que sua aprovação fosse postergada para junho de 2014 e, desse modo a vigência do plano será de 2014 a 2024.

${ }^{2}$ No decorrer do texto será tratado apenas como Manifesto.
} 
teoria da educação, a política educacional, assim como a prática pedagógica em todo o país. (SAVIANI, 2004, p.35).

O segundo é a promulgação da Constituição da República Federativa do Brasil de 1988 (CF 1988). “A constituição de 1988 fecha o círculo em relação ao direito à educação e à obrigatoriedade escolar na legislação educacional brasileira, recuperando o conceito de educação como direito público subjetivo, abandonado desde a década de 30.” (HORTA, 1998, p. 25).

Podemos afirmar, portanto, que esses dois documentos sintetizam o espírito democrático que as lideranças acadêmicas têm defendido há décadas no Brasil.

A respeito, dessa temática, contamos com ricos textos e reflexões. Sobre a atualidade do Manifesto, destaca-se a publicação intitulada "O Sistema Nacional de Educação: diversos olhares 80 anos após o Manifesto” organizada por Célio da Cunha (UNB), Moacir Gadotti (USP), Genuíno Bordignon (UNB), Flavia Nogueira (UFMT), lançada pelo Ministério da Educação (MEC) por meio da Secretaria de Articulação com os Sistemas de Ensino (SASE), no ano de 2014. Este trabalho contém textos de expositores que participaram da Conferência "O manifesto dos Pioneiros da Educação Nova e o Sistema Nacional de Educação”, realizada na Faculdade de Educação da USP.

Já em relação aos debates sobre a CF 1988, destacamos a publicação do número 2 do volume 29 da Revista Brasileira de Política e Administração da Educação (RBPAE ISSN 1678-166X) que teve como tema “A Constituição Federal 25 anos depois: balanços e perspectivas da participação da sociedade civil nas políticas educacionais.” Este estudo contou com reflexões de importantes nomes da Educação Brasileira, em especial, o texto de Nalú Farenzena e Maria
Beatriz Luce "Financiamento da Educação e responsabilidades federativas: 25 anos de agenda constituinte.”

Em relação ao PNE existe uma diversidade de análises. Umas versam sobre a tramitação e avaliação do PNE 2001-2009³, outras foram realizadas concomitante ao processo de tramitação do atual PNE, dentre as quais destacamos o Livro "Plano Nacional de Educação (2011-2020): Avaliação e Perspectivas, organizado por Luiz Fernando Dourado no ano de 2011.E, por fim, a partir do segundo semestre de 2014 começam a surgir os textos que analisam o texto final aprovado pela Lei 13.005/2014. O MEC, por meio do sítio on-line, fornece rico material para discussão do plano ${ }^{4}$.

Mais recentemente, a crise político-econômica, agravada no segundo mandato da Presidenta Dilma Roussef que culminou no seu impedimento e na assunção de seu vice Michel Temer à presidência da república, trouxe um novo contexto político que proporcionou a aprovação da Emenda Constitucional 95 promulgada pelo Congresso Nacional no dia 15 de dezembro de 2016. A referida emenda altera a CF 1988 por meio da inserção de novos artigos, no Ato das Disposições Constitucionais transitórias, com intuito de instituir um "Novo Regime Fiscal” que, nada mais são que uma limitação imposta aos gastos públicos no que concerne a despesas primárias ${ }^{5}$.

${ }^{3}$ Como exemplo podemos citar o Livro: Medo à Liberdade e Compromisso Democrático. (CURY; HORTA; ALVES DE BRITO, 1997) e o texto: Avaliação do Plano Nacional de Educação 2001-2009: questões estruturais e conjunturais de uma Política. (DOURADO, 2010)

${ }^{4}$ Em http://pne.mec.gov.br/ estão disponíveis o Texto Integral da Lei e seu Anexo, quatro publicações sobre o PNE, além de textos, artigos e indicações de outros sítios on-line sobre o assunto.

${ }^{5}$ Segundo posicionamento do próprio governo federal, exposta em sítio on-line do Orçamento Federal, as Despesas Públicas compreendem uma diversidade 
Retomemos pontos importantes destes documentos e leis citados para que possamos entender o paradoxo instaurado pela EC 95/2016.

A lei 13.005/2014, que “Aprova o Plano Nacional de Educação e dá outras Providências”, em seu texto, enfatiza a importância da colaboração dos entes Federados na organização da Educação Nacional. O artigo $7^{\circ}$ determina que o alcance das metas e estratégias propostas pelo PNE deverá ser realizado por meio do regime de colaboração, incumbindo cada ente da Federação de elaborar as estratégias adequadas para este fim, inclusive por meio de ações localizadas, indicando a criação de instâncias permanentes de negociação e, por fim, sugerindo, se necessário, a criação de Arranjos de Desenvolvimento ${ }^{6}$.

O MEC afirma que os papéis dos entes federados, em relação à garantia do direito à educação, estão definidos no texto da CF 1988, mas que embora exista esta definição de reponsabilidades ainda não existem normas que regulem a cooperação e a colaboração entre as diferentes instâncias da Federação.

de tipos de gastos. As despesas primárias seriam aquelas que "pressionam o resultado primário, alterando o endividamento líquido do Governo (setor público não financeiro) no exercício financeiro correspondente". Já as despesas não primárias ou financeiras são aquelas "que não pressionam o resultado primário ou não alteram o endividamento líquido do Governo (setor público não financeiro) no exercício financeiro correspondente, uma vez que criam um direito ou extinguem uma obrigação, ambas de natureza financeira, junto ao setor privado interno e/ou externo.” Ou seja, a EC 95/2016 institui um regime fiscal que tem impacto exclusivamente sobre os serviços executados pelo setor público, incidindo sobre Orçamento Fiscal e sobre a Seguridade Social, mas não sobre questões financeiras que dizem respeito, principalmente, ao endividamento da União.

6 “[...] o ADE se define por um trabalho em rede, no qual um grupo de municípios, com proximidade geográfica e características sociais e econômicas semelhantes, buscam trocar experiências e solucionar conjuntamente dificuldades na área da educação". (ARAÚJO, 2012, p. 518)
Assim, o PNE significa também uma oportunidade: se as diferentes esferas de governo têm compromissos comuns, terão resultados mais efetivos e recursos otimizados se planejarem suas ações de maneira integrada e colaborativa. Além desses claros benefícios, ao realizarem essa tarefa, os gestores indicarão caminhos concretos para a regulamentação dos pactos federativos nacionais em torno da política pública educacional, estabelecendo o primeiro desenho para o Sistema Nacional de Educação. (BRASIL, 2014, p. 9).

Dessa forma, o artigo 13 da Lei 13.005/2014 determina que no prazo de 2 anos de sua publicação, ou seja, até meados do ano de 2016, o poder público deverá oficialmente normatizar a criação do SNE, como instância permanente de negociação e organização do pacto federativo, garantindo o direito público subjetivo à Educação.

Como já citado, foi o Manifesto que primeiro abordou a importância de se organizar a educação nacional, sendo considerado como uma resposta dos intelectuais brasileiros ao contexto da época. Andreotti (2010) revela-nos que a década de 1930 ficou conhecida como marco da modernidade do Brasil, asseverando que no âmbito educacional destacam-se as disputas travadas entre os intelectuais liberais (escola-novistas em sua maioria) e os intelectuais católicos, a princípio, reunidos na Associação Brasileira de Educação e, posteriormente, cindidos devido a diferentes posicionamentos políticos ideológicos defendidos por ocasião da IV Conferência Brasileira de Educação ${ }^{7}$.

Representando o ideal LiberalDemocrata e buscando uma organicidade da Educação Nacional, o Manifesto apresentou-se como uma proposta de reconstrução educacional, pois segundo os seus signatários, um balanço da educação nacional da época, em

\footnotetext{
${ }^{7}$ A este respeito conferir Martins e Pinto (2014).
} 
especial dos anos iniciais da república, revelava uma política educacional fragmentária, dissociada das reformas econômicas e sem um espírito de continuidade. E, portanto, as ações e reformas realizadas pelos governos podiam ser caracterizadas como parciais e estritamente necessárias.

Saviani (2014) apresenta-nos os princípios filosóficos do Manifesto e afirma que com este embasamento os Pioneiros propuseram um Sistema Orgânico com base em uma escola primária que ao mesmo tempo em que se apoia nas escolas maternais e jardins de infância se articula com a educação secundária, que dão acesso às Escolas Superiores.

E para viabilizar esta proposta o Manifesto previa que:

A autonomia econômica não se poderá realizar, a não ser pela instituição de um "fundo especial ou escolar”, que, constituído de patrimônios, impostos e rendas próprias, seja administrado e aplicado exclusivamente no desenvolvimento da obra educacional, pelos próprios órgãos do ensino, incumbidos de sua direção. (MANIFESTO DOS PIONEIROS, 2006, p. 195).

Vemos que o desafio atual de se estabelecer uma articulação nacional de forma que o financiamento e políticas educacionais proporcionem o respeito à diversidade das regiões brasileiras sem desprezar a unidade de objetivos e a qualidade educacional já está posto na década de 1930 no Manifesto que postula unidade e multiplicidade.

Com efeito, ao afirmar que a unidade não implica uniformidade, mas pressupõe multiplicidade, o texto indica que, em lugar da centralização, é na doutrina federativa e descentralizadora que se baseará a organização de um sistema coordenado em toda a República, obedecendo a um plano comum, plenamente eficiente intensiva e extensivamente. (SAVIANI, 2014, p.21).
O ideário presente no manifesto, embora tenha um grande lastro na cultura acadêmica, que ao longo dos anos tem buscado a defesa da escola pública, não obteve êxito, haja vista que a concretização do SNE apresenta-se ainda como tarefa por fazer.

Podemos dizer que a proposta de reconstrução da educação nacional sofreu do mesmo mal que criticou: a fragmentação e a descontinuidade das políticas públicas no Brasil, o que pode ser constatado pelo trabalho científico de vários autores ${ }^{8}$.

A análise dos textos legais também demonstra esta situação. A constituição de 1934, influenciada pelo Manifesto, prevê a vinculação constitucional de recursos para Educação e prevê como competência da União a fixação de um Plano Nacional da Educação.

No entanto, esses dispositivos não chegaram a vigorar, seja em razão do advento do Estado Novo (como foi o caso do Plano Nacional de Educação), seja em razão de descumprimento por parte das instâncias federativas, como ocorreu com a vinculação orçamentária. (SAVIANI, 2014, p. 25)

Assim, a constituição de 1937 pode ser considerada o primeiro ato de descontinuidade e fragmentação, pois dela foi retirada a vinculação constitucional de recursos e embora incumbisse a União de fixar bases e diretrizes da Educação Nacional, isto não concretizou-se.

A constituição de 1946, retoma os preceitos da constituição de 1934 e estabelece os elementos de planejamento propriamente educacional que serão inaugurados pela LDB 4024/1961. No entanto, secundariza a ideia de plano.

Em 1964, com advento da ditadura militar novamente ocorre a descontinuidade

\footnotetext{
${ }^{8}$ Saviani (2014); Martins e Pinto (2014); Favero (2005); Cury, Horta e Brito (1997); Dourado (2011) Andreotti, Lombardi e Minto (2010); Cury (2007); Oliveira (2002) entre outros.
} 
política e o Brasil passa a viver seu período mais nebuloso, marcado por forte centralismo do poder, adesão a políticas propostas por mecanismos internacionais e pela afirmação do pensamento tecnocrático no campo educacional.

Após vinte anos de ditadura, o Brasil retoma o caminho democrático e a CF 1988 reafirma a primazia da Educação como Política Pública e a necessidade da colaboração dos entes federados para gerir de forma articulada a Educação Nacional, retomando os preceitos do Manifesto.

Dourado (2011) enfatiza que o Planejamento e as Políticas Educacionais, de nosso país, têm sido marcados por Políticas de Governo em detrimento de Políticas de Estado

E a propósito, para que haja continuidade e manutenção de ações e empreendimentos que visem à qualidade da escola pública é preciso que sejam asseguradas formas de financiamento.

A legislação brasileira prevê estas questões, no entanto, é preciso aprimorar e/ ou efetivamente implementar algumas delas.

Ao fazer outro retorno ao Manifesto, podemos constatar que este documento “[...] defendia que a solução dos problemas escolares fosse transferida do terreno administrativo para os planos políticos sociais.” (MARTINS; PINTO, 2014, p.164) e propunha a:

[...] criação de um fundo, como forma de dotar a educação de independência que afaste as "influências e intervenções estranhas que conseguiram sujeita-la a seus ideais secundários e interesses subalternos". Para tanto, propõe-se uma vasta autonomia técnica, administrativa e econômica, ficando a responsabilidade pela direção e administração da função educacional nas mãos de técnicos e educadores, assegurando-se os meios materiais para poderem realizá-la. (MARTINS; PINTO, 2014, p.167).
A análise feita por Martins e Pinto (2014), revela que é a partir do manifesto que a fórmula "autonomia + recursos vinculados" torna-se uma constante na política educacional brasileira, ora sendo adotada pelo texto legal ora sendo negligenciada. E demonstram que o Manifesto traz as primeiras formulações sobre a função supletiva da União.

Ou seja, os princípios federativos para consecução de uma educação pública estão postos no Manifesto e, são retomados pela CF 1988, que em seu artigo 211 prevê o regime de colaboração e a Ação supletiva da União; no artigo 212 a vinculação constitucional de recursos à Educação; no artigo 214 prevê o PNE e no Artigo 60 do ADCT a criação de um fundo especial de natureza contábil para as despesas educacionais.

O texto original da CF 1988 apresentava várias lacunas, o que ocasionou uma centralidade das discussões sobre financiamento educacional na agenda política pósconstituinte, fato comprovado pela análise de Farenzena e Luce (2013).

Também a atual LDBEN 9394/96, repete os preceitos constitucionais. Especificamente em seu Título VII trata "Dos Recursos Financeiros, sendo que o Art. 68 aborda a origem dos recursos; o Art. 69 a vinculação de receitas de cada ente federado; o Art 70 discrimina quais são as atividades consideradas manutenção e desenvolvimento do ensino e o Art 71 as que não são consideradas; os artigos 72 e 73 tratam respectivamente da apuração e fiscalização dos recursos; o Art. 74 versa sobre o regime de colaboração; os artigos 75 e 76 tratam da ação supletiva da União e, por fim, o Art. 77 determina a destinação dos recursos.

Dessa forma, a legislação brasileira posterior a CF 1988 possibilitou, não obstante as críticas cabíveis ${ }^{9}$, as bases para uma transformação do cenário educacional.

${ }^{9}$ Em relação a LDB, especialmente, podemos observar 
Contudo, o cenário educacional brasileiro começou a sofrer alterações com a criação do Fundo de Manutenção e Desenvolvimento do Ensino Fundamental e de Valorização do Magistério, FUNDEF, pela Lei 9424 de 24 de dezembro de 1996.

O FUNDEF, de acordo com Pinto (1999), é uma subvinculação de recursos, pois, como prevê a constituição, é um fundo com $15 \%$ das receitas previstas no cálculo da Vinculação Constitucional para área educacional. Ele possibilitou uma necessária expansão do Ensino Fundamental e induziu a Municipalização do Ensino. Existiram, porém, retrocessos como a não contemplação da Educação Infantil e do Ensino Médio, e o fato de que a criação do Fundo não gerou fontes adicionais de recursos para Educação.

Portanto, o FUNDEF foi uma iniciativa aquém das necessidades brasileiras. $\mathrm{O}$ autor reconhece, porém, a tendência de gerar um efeito “Robin Hood”, proporcionando uma melhor distribuição dos recursos.

Saviani também analisa o FUNDEF.

Numa apreciação sintética, de caráter conclusivo, cabe observar que, se essas medidas tinham o objetivo meritório de distribuir melhor os recursos tendo em vistas o financiamento do ensino fundamental, elas se limitaram, no entanto, a regular a aplicação de recursos já vinculados, não prevendo novas fontes de recursos e, além disso, reduzindo a participação da financeira da União [...] (SAVIANI, 2008, p. 88).

Mediante estas questões e da necessidade de se ampliar a atuação do Fundo para que a Educação Infantil e o Ensino Médio fossem contemplados, o FUNDEF foi substituído pelo Fundo de Manutenção e

análises que apontam, acertadamente, marcas do viés neolibeliralista que demarcou as Reformas Estatais a partir da década de 1990. A este respeito conferir MINTO (2010) e CURY, HORTA e BRITO (1997).
Desenvolvimento da Educação Básica e de Valorização do Magistério (FUNDEB).

Saviani (2008) destaca que a maior abrangência foi um dos dois avanços do FUNDEB. Outro avanço está expresso na Medida Provisória 339 de 28 de dezembro de 2006, que regulamenta o Art. 60 do ADCT e efetivamente cria o FUNDEB:

Art. $5^{\circ}$ A complementação da União destina-se exclusivamente a assegurar recursos financeiros aos Fundos, aplicando-se o disposto no caput do art. 160 da Constituição. $\S 1^{\circ}$ É vedada a utilização dos recursos oriundos da arrecadação da contribuição social do salário-educação a que se refere o $\S 5^{\circ}$ do art. 212 da Constituição na complementação da União aos FUNDOS. (BRASIL, 2006b, n.p.).

Com a impossibilidade de investir recursos da Quota do Salário-Educação (QSE) tem- se uma possibilidade de aumento dos investimentos da União.

A medida provisória 339 é, posteriormente, convertida em lei sendo que a Lei 11494 de 20 de junho de 2007 passa a regulamentar o FUNDEB.

O mecanismo de distribuição de recursos do Fundeb é similar ao que foi utilizado pelo Fundef, com a captação de recursos de Estados e municípios, além da complementação da União, e sua distribuição no âmbito de cada Estado e respectivos municípios, de acordo com as matrículas na educação básica. (SOUSA JUNIOR, 2006, p. 281).

Dessa forma, o FUNDEB é considerado um grande avanço, porém, como alerta Saviani (2008), este avanço não pode ser visto em termos de qualidade, pois os investimentos realizados embora tenham possibilitado a necessária expansão do atendimento educacional, ainda não são suficientes para 
a instauração de padrões mínimos de excelência educacional.

Em suma, para enfrentar os problemas que foram acumulando-se, os recursos orçamentários regulares não são suficientes. Impõe-se um plano de emergência que permita investir maciçamente, elevando-se substancialmente e em termos imediatos o percentual do PIB destinado à educação. Esta há de ser a idéia-força, o eixo central do PNE que devemos propor. (SAVIANI, 2008, p. 232)

Saviani propõe uma "outra política educacional”, com investimento maciço que compense o descaso histórico com o setor e efetive em uma política de Estado regida pelo Plano Nacional de Educação.

Pinto (1999) afirma que, embora seja um esforço considerável, a elevação dos investimentos educacionais a $10 \%$ do PIB, reivindicados pelos educadores brasileiros, é uma necessidade imposta pelos séculos de descaso educacional.

No entanto, o PNE (BRASIL, 2014, n.p.) aprovado prevê que:

Meta 20: ampliar o investimento público em educação pública de forma a atingir, no mínimo, o patamar de 7\% (sete por cento) do Produto Interno Bruto - PIB do País no 5o-(quinto) ano de vigência desta Lei e, no mínimo, o equivalente a $10 \%$ (dez por cento) do PIB ao final do decênio.

Assim, podemos concluir que as Políticas de Fundos propiciaram avanços, em especial no que se refere a ampliação da oferta educacional e a uma gestão mais transparente dos recursos, porém, não conseguiram sanar o problema crucial da Educação: a elevação dos investimentos ao patamar necessário e, mesmo com a aprovação do PNE (2014-2024), a urgência manifestada por acadêmicos e pela sociedade civil foi mais uma vez protelada e, caso a lei seja cumprida, teremos que esperar ainda uma década para vislumbrar avanços mais significativos.

No entanto, parece-nos que o fio de esperança, inaugurado pelo PNE, de que os próximos anos, mesmo que de forma tardia e lenta, assistiriam um crescente aumento dos investimentos em educação foi cortado pela EC 95/2016.

Polêmica, esta emenda começou a tramitar no Congresso Nacional por proposição do executivo e passou a tramitar na Câmara dos Deputados como Proposta de Emenda à Constituição (PEC) n 241/2016.

Nesta ocasião a PEC foi apresentada juntamente com anexo que consistia na "Exposição de Motivos Interministerial" $n^{\circ}$ 83/2016 elaborada conjuntamente pelo Ministério da Fazenda (MF) e pelo Ministério do Planejamento, Desenvolvimento e Gestão (MPDG) e consequentemente assinado pelos senhores Henrique de Campos Meirelles e Dyogo Henrique de Oliveira.

Neste documento ficam evidentes os reais motivos desta propositura, que estão bem sintetizados no item 21 do referido documento, onde se afirma que:

21. Um desafio que se precisa enfrentar é que, para sair do viés procíclico da despesa pública, é essencial alterarmos a regra de fixação do gasto mínimo em algumas áreas. Isso porque a Constituição estabelece que as despesas com saúde e educação devem ter um piso, fixado como proporção da receita fiscal. É preciso alterar esse sistema, justamente para evitar que nos momentos de forte expansão econômica seja obrigatório o aumento de gastos nessas áreas e, quando da reversão do ciclo econômico, os gastos tenham que desacelerar bruscamente. Esse tipo de vinculação cria problemas fiscais e é fonte de ineficiência na aplicação de recursos públicos. Note-se que estamos tratando aqui de limite mínimo de gastos, 
o que não impede a sociedade, por meio de seus representantes, de definir despesa mais elevada para saúde e educação; desde que consistentes com o limite total de gastos. (BRASIL/MF/MPDG, 2016, n.p.).

Dessa maneira, fica evidente que a propositura desta Emenda, tem o claro objetivo de neutralizar o dispositivo legal da vinculação constitucional de recursos às áreas de Saúde e Educação.

Romualdo Portela de Oliveira (2002), pesquisador da Faculdade de Educação da USP (FEUSP), relata que a ideia da vinculação constitucional de recursos remonta ao Império com propostas realizadas pelo Senador João Alfredo e, na revisão constitucional de 1925, reaparece novamente com Afrânio Peixoto.

No entanto, a vinculação será prevista somente na CF de 1934. Oliveira (2002) aponta ainda para a vida curta desta primeira vinculação em virtude do golpe de Estado de 1937. "Depois de 1934, a vinculação aparece e desaparece sistematicamente nos sucessivos textos constitucionais e na legislação educacional decorrente.” (OLIVEIRA, 2002, p. 97). O Brasil vive então seu primeiro período ditatorial entre os anos de 1937 e 1945. “A Constituição (outorgada) de 1937 retirou a vinculação constitucional de recursos para a educação, tal como ocorrerá 30 anos mais tarde, já sob outro regime autoritário.” (CURY, 2007, p. 836).

Esta tônica prossegue com a sucessão de períodos democráticos e autoritários e consequentemente com a retomada e posteriormente retirada do texto legal do dispositivo da Vinculação Constitucional de recursos que vai ser reafirmado pela atual CF.

A vinculação constitucional de recursos para a Educação é, portanto, de extraordinária importância, no cenário brasileiro, primeiramente por "decretar" a primazia da Educação perante as demais políticas sociais e, em segundo, por garantir que a destinação de receitas não estará à mercê de interesses partidários.

Com o intuito de novamente neutralizar este disposto que protegia a educação, a PEC 241 foi analisada pela Câmara dos Deputados e após deliberações e algumas emendas ao projeto (que não causaram mudança substancial) foi aprovada e encaminhada ao Senado Federal onde passou a tramitar como PEC $55 / 2016$.

Nesta segunda casa Legislativa a tramitação ocorreu de maneira similar à da Câmara dos Deputados e culminou na sua promulgação.

Aprovada tornou-se a EC 95/2016 que insere no Ato das Disposições Constitucionais Transitórias os Artigos 106, 107, 108, 109, 110, 111, 112, 113 e 114.

Impondo limites para as despesas primárias dos próximos 20 exercícios financeiros (vinte anos). E no artigo 110 do ADCT a redação que passa a vigorar é a seguinte:

Art. 110. Na vigência do Novo Regime Fiscal, as aplicações mínimas em ações e serviços públicos de saúde e em manutenção e desenvolvimento do ensino equivalerão:

I - no exercício de 2017, às aplicações mínimas calculadas nos termos do inciso I do $\S 2^{\circ}$ do art. 198 e do caput do art. 212, da Constituição Federal; e

II - nos exercícios posteriores, aos valores calculados para as aplicações mínimas do exercício imediatamente anterior, corrigidos na forma estabelecida pelo inciso II do $\S 1^{\circ}$ do art. 107 deste Ato das Disposições Constitucionais Transitórias.» (BRASIL, 2016, n.p.).

Vemos, portanto, que, como regra de transição, no ano de 2017 os percentuais mínimos propostos pelo mecanismo de vinculação 
de recursos devem ser respeitados e, a partir do ano de 2018 a vinculação passa a ser limitada (neutralizada) pelo Novo Regime Fiscal.

Devemos, contudo, reconhecer a eficiência do atual governo ao propor esta medida. Busquemos esclarecer o porquê julgamos assim.

O governo instaurado após o impedimento da Presidenta Dilma Roussef se propôs desde o início a compactuar com os anseios do mercado, enxergando, nesta postura, uma alternativa à governabilidade e consequentemente para superação da crise instaurada. Por compactuar com o mercado, o governo via-se impossibilitado de atuar sobre as despesas financeiras, haja vista, que isto implicaria em uma ação sistemática de grandes amplitudes como auditar a dívida pública, por exemplo, que teria forte impacto sobre os setores aliados.

Dessa maneira, a alternativa disponível a esta postura neoliberal é atuar sobre os gastos primários. Tal tipo de postura não é novidade e o contingenciamento de despesas no setor público é frequente. Neste momento, no entanto, o governo almejava uma ação mais radical e profunda de cortes de gastos públicos, meta esta que tinha como principal óbice a vinculação constitucional de recursos à Saúde e à Educação.

Tal obstáculo apresentava-se de grande monta, pois, a limitação à ação de contingenciamento proposta pelo executivo federal estava expressa na Lei Suprema da Nação, ou seja, na CF. Desse modo, o único meio de neutralizar este obstáculo foi o de inserir, por meio de Emenda, uma restrição a Vinculação Constitucional no próprio texto da CF.

E é por isso que, mesmo repudiando tal atitude, acreditamos que o governo logrou êxito e demonstrou-se eficiente na consecução de seus ardis.
A este respeito, é preciso destacar a incoerência desta ação que ao seguir os trâmites legais previstos para se emendar a CF busca camuflar a sua inconstitucionalidade.

O Boletim Legislativo $\mathrm{n}^{\circ} 53$ de Novembro/2016 emitido pelo Núcleo de Estudos e Pesquisas da Consultoria Legislativa do Senado Federal, de autoria do Consultor Legislativo Ronaldo Jorge Araújo Vieira Junior, apontava vários problemas na, então em tramitação, PEC 55/2016, elencando sua inconstitucionalidade por violar cláusulas pétreas da CF.

Segundo Vieira Junior, o novo regime comete este tipo de inconstitucionalidade ao violar: o princípio da separação dos poderes; o princípio da segurança jurídica, o princípio da razoabilidade; o voto direto, secreto universal e periódico; o princípio da intranscendência da pena em sua dimensão institucional; o princípio da vedação do retrocesso social.

Para nós, interessa, em especial, a última violação mencionada pelo autor. Vieira Junior demonstra, com segurança, que o congelamento dos gastos em educação ao montante gasto no ano 2017 corrigido, nos anos subsequentes, pelo Índice de Preços ao Consumidor Amplo (IPCA) como prevê o Novo Regime Fiscal, promoverá verdadeiro retrocesso social, pois inviabiliza o necessário aumento dos investimentos na educação que em nosso país não conseguiu ainda universalizar todos os níveis de educação, assim como não é capaz de promover patamares mínimos de qualidade. Ademais inviabiliza a consecução da meta vinte da lei 13.005/2014 (PNE).

Eis, portanto, a constatação do paradoxo atual: temos, ao mesmo tempo, no texto legal (CF 1988) a garantia da primazia educacional por meio do dispositivo da vinculação constitucional de recursos e a sua neutralização por meio da limitação dos gastos públicos. 


\section{Notas conclusivas}

Com base nesta breve revisitação da literatura e da legislação educacional, podemos perceber que o problema do Financiamento Educacional da Educação Pública Brasileira nunca esteve perto de sua resolução.

A fragmentação, a protelação e o descumprimento dos preceitos legais têm se despontado como principal razão deste cenário.

A agenda de políticas públicas para o Financiamento Educacional e as demandas evidenciadas pelos pesquisadores acadêmicos, assim como pela sociedade civil organizada, têm orbitado em torno de questões como: Políticas de Fundos, Vinculação Constitucional de Recursos (e outras garantias de patamares mínimos de investimentos), Implementação do SNE e Controle Social dos Recursos. Questões estas que já haviam sido postas desde a década de 1930 com o Manifesto dos Pioneiros.

Após a CF 1988, a criação do FUNDEF e sua posterior substituição pelo FUNDEB e, mais recentemente a aprovação da Lei 13.005/, 2014 (PNE) levaram a um clima otimista sobre o financiamento educacional, onde acreditava-se que, embora de forma lenta e na maioria das vezes negligenciada, estávamos conseguindo sólidos e duradouros avanços para área.

Contudo, o contexto sócio-político-econômico, que se configurou a partir do ano de 2016, levou a uma drástica mudança de perspectiva, por meio da aprovação da EC 95/2016 que limita os gastos públicos nos próximos vinte exercícios financeiros, evidenciando um cenário de retrocesso dos investimentos educacionais.

Com base nestes dados, somos impelidos a afirmar que um constante e progressivo incremento do investimento em Educação está muito distante de se concretizar e que, no âmbito das políticas públicas, ainda prevalece a máxima da política brasileira de promover arbitrariamente descontinuidades a fim de atender interesses particulares.

Esta situação indica-nos que os tempos vindouros demandarão muita mobilização da sociedade civil e um forte empenho acadêmico na luta em defesa pela democratização do ensino que somente será viabilizada por uma política de Financiamento Educacional efetiva, duradoura e desvinculada de interesses político/partidários.

\section{Referências}

ANDREOTTI, A. L. A administração escolar na Era Vargas (1930-1945). In: ANDREOTTI, A. L.; LOMBARDI, J. C.; MINTO, L. W. (Orgs.). História da administração escolar: do diretor ao gestor. Campinas: Alínea, 2010. p. 103-123.

ANDREOTTI, A. L.; GALINDO, J. A administração escolar no nacional desenvolvimentismo (1946-1964). In: ANDREOTTI, A. L.; LOMBARDI, J. C.; MINTO, L. W. (Orgs.). História da administração escolar: do diretor ao gestor. Campinas: Alínea, 2010. p. 125-145.

ARAÚJO, G. C. Federalismo cooperativo e arranjos de desenvolvimento da educação: o atalho silencioso do empresariado para a definição e regulamentação do regime de cooperação. RBPAE, Goiânia, v. 28, n. 2, p. 515-531. maio/ago. 2012

BRASIL. Emenda Constitucional $\mathbf{n}^{0} \mathbf{9 5}$ de 15 de dezembro de 2016. Disponível em: <http://www.planalto.gov.br/ccivil_03/ constituicao/emendas/emc/emc95.htm>. Acesso em: 21 abr. 2017.

\section{MF/MPDG. Exposição de}

Motivos Interministerial $n^{0} \quad 83 / 2016$.

Disponível em: <http://www.camara.gov. 
br/proposicoesWeb/prop_mostrarintegra ;jsessionid=77A95F3DEAC0FA84D812 BF8394494121.proposicoesWebExterno2 ?codteor $=1468431 \&$ filename $=$ TramitacaoPEC+241/2016>. Acesso em: 21 abr. 2017.

Ministério da Educação. Planejando a próxima década. Conhecendo as 20 metas do Plano Nacional de Educação. Brasília: MEC/SASE, 2014. Disponível em: <http://pne.mec.gov.br/images/pdf/pne_ conhecendo_20_metas.pdf $>$. Acesso em: 21 abr. 2017.

Ministério da Educação e Cultura (MEC). Portaria Interministerial $\mathbf{n}^{\mathbf{0}} 04$ de 7 de maio de 2013. Disponível em: <http:// www.fnde.gov.br/fnde/legislacao/portarias/ item/4501-portaria-interministerialn\%C2\%BA-4,-de-7-de-maio-de-2013>. Acesso em: 15 abr. 2014.

Ministério da Educação e Cultura (MEC). Módulo FUNDEB. Brasília: MEC, FNDE, 2010.

Lei $\mathbf{n}^{0}$ 11.494, de 20 de junho de 2007. Disponível em: <http://www.planalto. gov.br/ccivil_03/_ato2007-2010/2007/lei/ l11494.htm>. Acesso em: 15 abr. 2014.

Emenda Constitucional $\mathbf{n}^{\mathbf{0}}$ 53, de 19 de dezembro de 2006a. Disponível em: <http://www.planalto.gov.br/ccivil_03/ constituicao/Emendas/Emc/emc53.htm>. Acesso em: 15 abr. 2014.

Medida Provisória $n^{0}$ 339, de 28 de dezembro de 2006b. Disponível em: $<$ http://portal.mec.gov.br/seb/arquivos/pdf/ Fundebef/fundeb_mp.pdf $>$. Acesso em: 15 abr. 2014.

Lei $\mathbf{n}^{\circ}$ 9394, de 20 de dezembro de 1996a. Disponível em: <http://www. planalto.gov.br/ccivil_03/leis/19394.htm>. Acesso em: 15 abr. 2017.
. Emenda Constitucional $n^{\circ}$ 14, de 12 de setembro de 1996b. Disponível em: <http://www.planalto.gov.br/ccivil_03/ constituicao/Emendas/Emc/emc14.htm>. Acesso em: 15 abr. 2014.

Lei $\mathbf{n}^{\circ}$ 9424, de 24 de dezembro de 1996c. Disponível em: <http://www. planalto.gov.br/ccivil_03/leis/19424.htm>. Acesso em: 15 abr. 2014.

$$
\text { Constituição }
$$

(1988).

Constituição da República Federativa do Brasil. Disponível em: <http://www. planalto.gov.br/ccivil_03/constituicao/ constituicaocompilado.htm>. Acesso em: 15 abr. 2017.

CARNOY, M. Educação, economia e Estado: base e superestrutura: relações e mediações. São Paulo: Cortez: Autores Associados, 1987.

CURY, C. R. J. Estado e Políticas de Financiamento em Educação. Educação e Sociedade, Campinas, v. 28, n.100, p. 831855, out. 2007.

. A educação e a primeira constituinte republicana. In: FÁVERO, O. (Org). A educação nas constituintes brasileiras 1823-1988. Campinas: Autores Associados, 2005. p. 69-80.

FARENZENA, N.; LUCE, M. B. Financiamento da educação e responsabilidades federativas: 25 anos de agenda constituinte. RBPAE, Goiânia, v. 29, n.2, p. 263-281, maio/ago. 2013.

HORTA, J. S. B. Direito à educação e obrigatoriedade escolar. Caderno de Pesquisa, São Paulo, Fundação Carlos Chagas, n.104, p. 5-34, jul. 1998.

LOURENÇO FILHO, M. B. Organização e administração escolar: curso básico. São Paulo: Melhoramentos, 1976. 
MANIFESTO DOS PIONEIROS DA EDUCAÇÃO NOVA, 1932. Revista HISTEDBR [online], Campinas, $\mathrm{n}$. especial, p. 188-204, ago. 2006. Disponível em: <http://www.histedbr.fae.unicamp.br/ revista/edicoes/22e/doc1_22e.pdf $>$. Acesso em: 13 mar. 2014.

MARTINS, P. S. M.; PINTO, J. M. R. Como seria o financiamento de um sistema nacional de educação na perspectiva do Manifesto dos Pioneiros da educação nova. In: CUNHA, C.; GADOTTI, M.; BORDIGNON, G.; NOGUEIRA, F. Sistema Nacional de Educação: diversos olhares 80 anos após o Manifesto. Brasília: MEC/SASE, 2014. p. 156-181.

PINTO, J. M. R. Um fundinho chamado Fundão. In: DOURADO, J. F. (Org.). Financiamento da educação básica. Campinas: Autores Associados; Goiânia: Editora da UFG, 1999. p. 85-98.

OLIVEIRA, R. P. de. O financiamento da educação. In: ADRIÃO, T.; OLIVEIRA, R. P. de. (Orgs.). Gestão, financiamento e direito à educação: análise da $\mathrm{LDB}$ e da Constituição Federal. São Paulo: Xamã, 2002a. p. 83-122.

. O direito à educação. In: ADRIÃO, T.; OLIVEIRA, R. P. de. (Orgs.). Gestão, financiamento e direito à educação: análise da LDB e da Constituição Federal. São Paulo: Xamã, 2002b. p. 15-43.

RODRIGUES, A. T. Sociologia da educação. Rio de Janeiro: DP\&A, 2000.

RODRIGUES, C. A. F. Estado, política e sociedade. In: OLIVEIRA, R. C. S. (Org.). Sociologia: consensos e conflitos. Ponta Grossa: Editora UEPG, 2001. p.111-148.

SAVIANI, D. Sistema de eucação: subsídios para a Conferência Nacional de Educação. Disponível em: <http://conae.mec. gov.br/ images/stories/pdf/conae_dermevalsaviani. pdf> . Acesso em: 15 out. 2013.

Da nova LDB ao FUNDEB: por uma outra política educacional. Campinas: Autores Associados, 2008.

O legado educacional do "longo Século XX” brasileiro. In: SAVIANI, D. et al. O legado educacional do século XX no Brasil. Campinas: Autores Associados, 2004. p. 9-57.

SOUSA JUNIOR, L. FUNDEB: avanços, limites e perspectivas. EccoS - Revista Científica, São Paulo, v. 8, n. 2, p. 275-290, jul./dez. 2006.

VIEIRA JUNIOR, R. J. A. As inconstitucionalidades do "novo regime fiscal” instituído pela PEC n ${ }^{\circ}$ 55, de 2016 (PEC $\mathrm{n}^{\circ}$ 241, de 2016, na câmara dos deputados). In: Boletim Legislativo $\mathbf{n}^{\mathbf{0}} \mathbf{5 6}$ : Novembro/2016. Disponível em: <https:// www12.senado.leg.br/publicacoes/estudoslegislativos/tipos-de-estudos/boletinslegislativos/bol53>. Acesso em: 21 abr. 2017. 